\title{
In Vitro Evaluation of the Impact of Erosive/Abrasive Challenge in Glass Ionomer Cements
}

\section{Cinthia Maria Baggio de Luca Cunha, Letícia Maíra Wambier, Gisele Fernandes Dias, Alessandra Reis, Fabiana Bucholdz Teixeira Alves, Ana Cláudia Rodrigues Chibinski* and Denise Stadler Wambier}

Department of Pediatric Dentistry, Ponta Grossa State University, Brazil

Received: September 21, 2017; Published: October 05, 2017

*Corresponding author: Ana Claudia Rodrigues Chibinski, Departament of Pediatric Dentistry, School of Dentistry, Ponta Grossa State University General Carlos Cavalcanti Avenue, Brazil

\begin{abstract}
To evaluate the loss of mass and the surface roughness of glass ionomer cements (GIC) after acid challenge (erosion) and simulated tooth brushing (abrasion). Methods: Ten specimens of each GIC were made: Vidrion R® (VR) (SS White), Maxxion R® (MX) (FGM) Riva Self Cure ${ }^{8}$ (RV) (SDI) and Gold Label Light Cured ${ }^{\circledR}$ (GL) (GC). The mass of the materials was verified before and after the erosion/abrasion challenge. At the same moments, the mean surface roughness was measured in each specimen using a surface profile meter. The erosion was produced immersing the specimens in an acid soft drink and in artificial saliva in 5s cycles alternately for 10 times. After that, they were submitted to simulated tooth brushing (20.000 cycles of brushing). Data were evaluated using ANOVA and Tukey post test. Results: The erosive/abrasive challenge didn't result in significant loss of mass ( $\mathrm{p}=0.009)$, but increased the final surface roughness in all GICs $(\mathrm{p}<0.001)$. The higher surface roughness was observed for conventional GICs (MX and VR), followed by RMGIC (VR) and the encapsulated GIC (RV). Conclusion: It is concluded that the erosive and abrasive processes increased the surface roughness in GICs and the encapsulated GIC was the less affected by the surface wear factors studied.
\end{abstract}

Keywords: Beverages; Dental restoration wear; Glass ionomer cement; Tooth brushing; Tooth erosion.

\section{Introduction}

The tooth erosion is a problem of increasing complexity in Dentistry that affects children, teenagers and adults. It is characterized by a pathologic wear of the mineralized tooth structures, in a cumulative process that may generate severe losses to enamel and dentin [1]. The erosion is related to intrinsic etiological factors, like stomach acids, or extrinsic factors like the elevated consume of acid beverages and foods. Data shows that half $(51.6 \%)$ of the Brazilian pre-scholar children (35-59 months old) exhibits pathological wear caused by tooth erosion [2]. In a recent meta-analysis that collected data from different countries, this index is $34.1 \%$ [3]. It's common for the erosion lesions to require restorative procedures to return function or esthetics [4]. Unfortunately, the erosion process affects not only the tooth structure. Its effects are also experienced by the restorative materials. As a result, their properties are affected, particularly on the surface that is exposed to the oral environment.

The ideal surface for a restoration must be smooth and regular. But under the effects of erosion, the outer layer of the restorative material is gradually transformed into a rough surface $[1,5]$. This will favor the dental biofilm accumulation, the demineralization in the tooth-restoration interface and gingival irritation [6]. In this situation, we should consider yet the influence of tooth brushing that adds a mechanical component to the whole process. The association between the erosion caused by acid food and drinks and the abrasion induced by the toothbrush/dentifrice may exert a synergic effect in the superficial wear of the restorative materials. Therefore, the materials properties are altered $[1,5]$.

The glass ionomer cement (GIC) is one of the suitable restorative materials to restore erosive lesions due to GIC properties like adhesion to enamel and dentin, biocompatibility and fluoride release [7]. The conventional GICs tend to be less resistance to the chemical and mechanical challenges imposed by the oral environment $[8,9]$. However, the development of the resin modified GIC (RMGIC), the high viscosity GIC and the encapsulated GIC tried to overcome this problem, since they exhibit better physical and mechanical properties that may enhance GIC use in Dentistry $[10,11]$. The clinical longevity of the dental materials over the time is determined by their capacity to resist to acid and mechanic challenges in a daily basis. Therefore, this paper objective was to evaluate the changes in mass and surface roughness of 
conventional, resin modified and encapsulated glass ionomer cements after erosion and abrasion processes.

\section{Material and Methods}

Four different types of GIC were tested: two conventional GICs - Vidrion $\mathrm{R}^{\circledR}$ (SS White)-VR and Maxxion $\mathrm{R}^{\circledR}$ (FGM)-MX; one encapsulated GIC - Riva Self Cure ${ }^{\circledR}(\mathrm{SDI})$-RV and one RMGIC - Gold Label Light Cured ${ }^{\circledR}$ (GC)-GC (Table 1). Forty specimens (10 for each material) were made using silicone patterns $(5 \mathrm{~mm}$ thickness $\mathrm{X} 6 \mathrm{~mm}$ diameter). The GICs were manipulated according to the manufacturer's instructions. After the complete filling, the patterns were covered with polyester strips and a glass slab. The specimens were kept under pressure for about 1 minute, in order to pour out the excess of the material and to obtain a smooth surface. For the RMGIC group, the specimens were photo polymerized for 40s (LEDRadii-Cal, SDI, Bays water, Australia; $600 \mathrm{mWcm}^{-2}$ ).

All the specimens were carefully removed from the patterns and the excesses were taken away with sandpaper discs and scalpel blades before applying a layer of solid petroleum jelly. This last step aimed to avoid the uptake or loss of water by the GICs. Before the beginning of the tests, each specimen was kept in an individual and identified recipient with distilled water at $37^{\circ} \mathrm{C}$.

\section{Mass measurement}

After 24 hours, the specimens were weighted in an analytical scale. This procedure was repeated until a constant weight was achieved. This indicated that the mass wouldn't be influenced by uptake or loss of water during storage [12]. The mass of the specimens were registered in grams before - initial mass (IM) and after - final mass (FM) the erosive/abrasive challenge. For the measure of the mass, the specimens were removed from the individual recipient, dried with absorbent paper for 30s and positioned in the analytical scale (precision=0.0002g; AW 220-Shimadzu do Brazil Ltda., São Paulo, SP-Brazil). This protocol was repeated three times for each specimen. The IM or FM was considered the mean of these three measurements.

\section{Roughness measurement}

The surface roughness (Ra) was obtained before (initial roughness - Ri) and after (final roughness - Rf) in a contact profilometer (Surftest-301, n. de série 15700438, Mitutoyo- Japan). It was calibrated using a pattern plaque for mean roughness of $2.95 \mu \mathrm{m}$. The cut-off limit was $0.25 \mu \mathrm{m}$ in order to minimize the interference of the surface ondulation. The measurement limit was $1.25 \mathrm{~mm}$. In order to evaluate a significant area in each specimen, the surface roughness reading were done in five spots in the surface of the specimens. The Ri or Rf values correspond to the mean of these five readings.

\section{Acid challenge}

The specimens were immersed in an acid drink (Coke ${ }^{\circledR}$ ) for 5 seconds, followed by immersion on artificial saliva (5s). These cycles were repeated alternately for 10 times. The Coke ${ }^{\circledR}$ acidity was verified before the acid challenge in $\mathrm{pH}$-meter (PG
1400-GEHAKA) at a mean temperature of $14^{\circ} \mathrm{C}$. The artificial saliva was prepared according to the formula: Nipagin $0,05 \%$; potassium chloride $0,0625 \%$; sodium chloride $0,0865 \%$; magnesium chloride $0,0056 \%$; calcium chloride $0,0166 \%$; two phase potassium phosphate $0,0803 \%$; monobasic potassium phosphate $0,0326 \%$; sodium fluoride $0,002 \%$; sodium benzoate $0,1 \%$; CMC $0,4 \%$ e purified water in a sufficient quantity to make $100 \mathrm{ml}$.

\section{Simulated toothbrush}

The specimens were adapted in the tooth brushing machine (ElQuip, São Carlos, SP-Brazil). The machine executed back and forth movements with ten metallic arms where ten soft toothbrushes (NOS@LIG Produtos Odontológicos Ltda, Tabuão da Serra, São Paulo, Brazil) are engaged. The tooth brushing was performed with a slurry to mimic the saliva dilution that occurs in the mouth. The slurry was made with one part the dentifrice Colgate Total (Colgate-Palmolive Division Kolynos Brazil, Osasco, São Paulo, Brazil) and two parts of water. It was mixed in a magnetic stirrer without heating (Fisatom, São Paulo, São Paulo, Brazil) and placed in disposable syringes of $20 \mathrm{ml}$.

The syringes were attached to the brushing machine, which injected $2 \mathrm{ml}$ every 2 minutes during the tooth brushing cycle. The specimens were positioned in the machine using a special metallic matrix. About $2 \mathrm{~mm}$ of the specimens were left outside the matrix, in order to keep the contact of the toothbrush only with the GIC specimens. The specimens were subjected to a 20.000 tooth brushing cycle, with a load of $250 \mathrm{gf}$, a speed of 4.5 movements/s and a temperature of $37 \pm 0.3^{\circ} \mathrm{C}$. After the cycle, the specimens were kept in an ultrasonic tank (Cristófoli, Campo Mourão, Paraná, Brazil) for 10 minutes to remove the residues of dentifrice. After that, they were dried and the final mass and surface roughness from each specimen was obtained. Finally, the specimens were stored in their individual recipients with distilled water.

\section{Statistical Analysis}

The comparisons between the four GICs for loss of mass and surface roughness before and after erosive/abrasive challenges were accomplished using two ways ANOVA with repeated measures and Tukey post test. The significance level was set at 0.05 . All analysis was done using the software Graph Pad Prism (version 5.0 for Windows-Graph Pad Software, Inc.San Diego, USA).

\section{Results}

The interation between the main factors was not statistical significant $(\mathrm{p}=0.088)$. Therefore, the main factors (surface roughness and loss of mass) can be interpreted individually. The values are disposed in Significant differences were observed between initial and final surface roughness values in the same material $(\mathrm{P}=0.088)$ and between different GICs $(\mathrm{P}<0.001)$. There was an increase in the surface roughness in every tested GIC. The highest mean roughness was noted for MX, followed by VR, GC and TV (Table 1). The smallest loss of mass was observed in the RV. However, the statistical differences were not significant $(p=0.009)$ (Table 2). 
Table 1: Description of the glass ionomer cements tested in this study.

\begin{tabular}{|c|c|c|c|c|}
\hline Product & Manufacturer & Lot & Color & Composition \\
\hline Vidrion $\AA^{\mathrm{TM}}(\mathrm{VR})$ & SS WHITE & 10712 & $\mathrm{U}$ & $\begin{array}{c}\text { Powder: Sodium } \\
\text { fluorsilicate calcium and } \\
\text { aluminium, barium sulfate, } \\
\text { poly acrylic acid and } \\
\text { pigments. } \\
\text { Liquid: tartaric acid and } \\
\text { distilled water. }\end{array}$ \\
\hline Maxxion $\circledR^{\mathrm{TM}}(\mathrm{MX})$ & FGM & 90413 & A3 & $\begin{array}{l}\text { Powder: Glass of fluoro } \\
\text { aluminium silicate, calcium } \\
\text { fluoride and pigments. } \\
\text { Liquid: poly acrylic acid and } \\
\text { water. }\end{array}$ \\
\hline Riva self cure ${ }^{\mathrm{TM}}{ }^{\mathrm{N}}(\mathrm{RV})$ & SDI & 79192EG & $\mathrm{A} 1$ & $\begin{array}{l}\text { Powder: Aluminium } \\
\text { fluorsilicate, polya crylic } \\
\text { acid. } \\
\text { Liquid: Poly acrylic acid and } \\
\text { tartaric acid. }\end{array}$ \\
\hline Gold Label-GC $\AA^{\mathrm{TM}}$ (GC) & GC & 1211021 & A3 & $\begin{array}{l}\text { Powder: Glass of fluoro } \\
\text { aluminium silicate (95\%) } \\
\text { and - poly acrylic acid (5\%) } \\
\text { Liquid: - poly acrylic acid } \\
\text { (30-40\%) and distilled } \\
\text { water (50-55\%) }\end{array}$ \\
\hline
\end{tabular}

Table 2 : Means and standard deviations of superficial roughness measurement $(\mu \mathrm{m})$ and loss of mass $(\mathrm{g})$ of the glass ionomer cements tested after $\mathrm{pH}$-cycling regime and toothbrush abrasion.

\begin{tabular}{|c|c|c|c|}
\hline \multirow{2}{*}{ Material } & \multicolumn{2}{|c|}{ Surface Roughness (Ra) } & \multirow{2}{*}{ Mass (g) IM - FM } \\
\cline { 2 - 4 } & Initial & $2.11 \pm 0.6 \mathrm{bA}$ & $0.00446 \mathrm{~A}$ \\
\hline MX & $1.23 \pm 0.29 \mathrm{aA}$ & $1.43 \pm 0.97 \mathrm{bB}$ & $0.00078 \mathrm{~A}$ \\
\hline VR & $0.87 \pm 0.34$ aB & $1.27 \pm 0.61 \mathrm{bBC}$ & $0.00103 \mathrm{~A}$ \\
\hline GC & $0.87 \pm 0.45 \mathrm{aBC}$ & $0.68 \pm 0.18 \mathrm{bC}$ & $-0.00019 \mathrm{~A}$ \\
\hline RV & $0.49 \pm 0.21 \mathrm{aC}$ & & \\
\hline
\end{tabular}

\section{Discussion}

The associated factors erosion/abrasion to which the tested GICs were subjected resulted in increased surface roughness regardless the type of the GIC tested. The surface integrity of restorative materials is commonly tested in vitro using corrosive wear and brushing abrasion. Therefore, the corroded layers of the material are removed by the mechanical force and that association alters the surface texture Carvalho, Sampaio, 2012. As a result, there is degradation of the organic matrix, filler, or matrix-filler interface on the surface of the materials, leading to increased surface roughness and wear rate Carvalho, Sampaio, 2012.

To simulate the changes in the $\mathrm{pH}$ of the oral environment, the specimens were immersed alternately in Coke and artificial saliva, resulting in demineralization and mineralization moments. The frequency of soft drink ingestion is in direct proportion with its degradative potential Bajwa and Pathak 2014. In our study, the erosion cycle took 100 s to be completed and it was projected to simulate the act of drinking one can with $325 \mathrm{ml}$ of Coke
Wongkhantee, Patanapiradej 2006. Longer erosion cycles were purposed in the literature Carvalho, Sampaio 2012, Bajwa and Pathak 2014. Notwithstanding, the simplified cycle we used, that included 10 immersions of the specimens in Coke, was able to modify the roughness of the tested GICs. This along with the use of artificial saliva Bajwa and Pathak 2014 is probably an accurate way to simulate the oral environment and reproduce clinical situations In Vitro.

Coke was selected as the erosive agent because is the most drunk soft drink around the world and it has a high potential to produce erosion, which is related to the low $\mathrm{pH}(\sim 2.5)$ and the presence of an inorganic and strong acid (phosphoric acid) Bajwa and Pathak, 201). The conventional GICs Maxxion and Vidrion showed the highest surface roughness values in our sample. The same influence of acid solutions on GIC surface was observed by other researchers using different brands of conventional GICs Bala, Arisu 2012, Reddy, Kumar. This is explained by two main factors: the particle size and the reaction of hydrogen ions $(\mathrm{H}+)$ in acidic environment. 
Usually, materials with bigger average particle size tend to exhibit higher roughness Bala, Arisu 2012, Pacifici, Bossù. The conventional GICs present the larger mean sized particles when compared to RMGIC or high viscosity GIC Pacifici, Bossù 2013. These larger glass particles are immersed in a hydrogel matrix. In low $\mathrm{pH}$ mediums, the $\mathrm{H}+$ ions from the acid can diffuse into the bulk of the material and replace the metal cations in the matrix. When free, the cations are released from the GIC. This process induces more ions to be extracted from the glass particles, which dissolve slowly. As a result, the GIC surface will present voids and protruded un dissolved glass particles Bajwa and Pathak 2014, Reddy, Kumar,-2014. Since RMGIC exhibits smaller filler particles and a resin component that favors the surface smoothness, it was expected smallest values of surface roughness in the resin modified glass ionomer cement. However, the Gold Label Light Cured (GC) showed a level of surface roughness higher than Riva Self Cure.

That's because many other factors may influence roughness, like differences in shape, distribution, number of particles, interfacial bonding between particles and matrix Bala, Arisu, Reddy, Kumar 2014. In the RMGIC situation, we believe that the firmness of the cross linked polyacrylate network and the polymer chain of RMGIC is insufficient to protect the material from the acidic solutions. In the oral environment, when exposed to low $\mathrm{pH}$, the RMGIC tends to absorb water and become less resistant to surface degradation Bajwa and Pathak.

As for the encapsulated GIC, the good results of surface roughness obtained after erosion/abrasion challenge proved the importance of a careful handling of the GICs. Considering that Riva Self Cure (SDI) is a conventional GIC, it would be expected higher roughness values. But this didn't occurred, because encapsulated GIC presents superior mechanical properties when compared to hand-mixed ones Molina, Cabral 2013, since the mechanical handling of the GIC prevents the incorporation of voids or incorrect powder to liquid ratio. This may also have some influence in the loss of mass. Even we didn't find significant changes in the mass of the tested GICs after the erosion/abrasion challenge, the encapsulated GIC showed the smallest change in this criterion. Taken all together, it's important to point out that these results were obtained after a simulation of drinking only one can of Coke. Therefore, we should expect very higher surface roughness in a day-to-day basis, since a normal dietary intake would include other sources of acids that will act in synergy and probably produce greater surface changes.

\section{Conclusion}

The erosive/abrasive challenge increased the surface roughness for all the tested glass ionomer cements, with the encapsulated GIC achieving the best. The loss of mass was not affected by the challenge.

\section{References}

1. Jaeggi T, Gruninger A, Lussi A (2006) Restorative therapy of erosion. Monogr Oral Sci 20: 200-214.

2. Murakami C, Tello G, Abanto J, Oliveira LB, Bonini GC, et al. (2015) Trends in the prevalence of erosive tooth wear in Brazilian preschool children. International Journal of Paediatric Dentistry 26(1): 60-65.

3. Salas MM, Nascimento G, Vargas-Ferreira F, Tarquinio SB, Huysmans, et al. (2015) Diet influenced tooth erosion prevalence in children and adolescents: results of a meta-analysis and meta-regression. Journal of dentistry 43(8): 865-875.

4. Goyel P, Singh M, Bansal R (2013) Comparative evaluation of erosive potential of different beverages on enamel and tooth colored restorative materials: An in vitro study. Journal of Pediatric Dentistry 1: 58.

5. Rios D, Santos FC, Honorio HM, Magalhaes, Wang L, et al. (2011) An in situ/ex vivo comparison of the ability of regular and light colas to induce enamel wear when erosion is combined with abrasion. Quintessence Int 42: e44-e50.

6. Steinberg D, Eyal S (2002) Early formation of Streptococcus sobrinus biofilm on various dental restorative materials. J Dent 30: 47-51.

7. Salas C, Guglielmi C, Raggio D, Mendes FM (2011) Mineral loss on adjacent enamel glass ionomer cements restorations after cariogenic and erosive challenges. Archives of oral biology 56: 1014-1019.

8. Turssi CP, Hara AT, Serra MC, Rodriques AL, et al.(2002) Effect of storage media upon the surface micromorphology of resin-based restorative materials. J Oral Rehabil 29: 864-871.

9. Beriat NC, Nalbant D (2009) Water Absorption and HEMA Release of Resin-Modified Glass-Ionomers Eur J Dent 3(4): 267-272.

10. Zoergiebel J, Ilie N (2013) Evaluation of a conventional glass ionomer cement with new zinc formulation: effect of coating, aging and storage agents. Clin Oral Investig 17: 619-626.

11.Al-Angari SS, Hara AT, Chu TM, Platt J, Eckert G, et al. (2014) Physicomechanical properties of a zinc-reinforced glass ionomer restorative material J Oral Sci 56: 11-16.

12. Thomassewski, MHD, Santos, dos FA, Wambier, et al. (2009) Desgaste dos cimentos de ionômero de vidro indicados para tratamento restaurador atraumático, após escovação simulada. Revista de Odontologia da UNESP 38: 135-142.

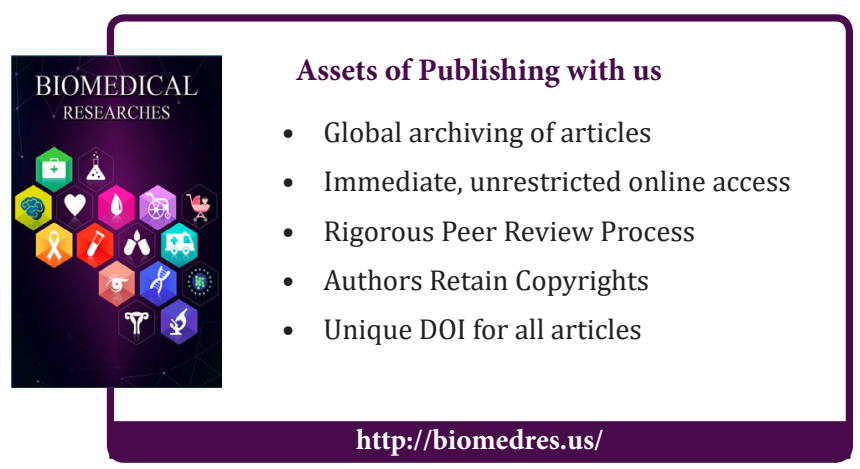

